\title{
48. Independent Relative Vertical Movements of Land Blocks as Revealed by Means of Repeated Precise Levellings along the Western Coast of Idu Peninsula.
}

By Chûji Tsubor.

Earthquake Research Institute, Tokyo Imperial University.

(Rec. April 10, 1931. Comm. by T. Terada, M.I.A., April 13, 1931.)

After the destructive North Idu earthquake Nov. 26, 1930, a revision of precise levellings was made around and across Idu Peninsula by the Land Survey Department, the results of which were recently placed at our disposal. The results of the new survey were compared with those of the earlier survey (1923-1929) made along the same route and some remarkable changes were found to have been produced in the heights of the bench marks in the measured route. Most of these changes, if not whole, is to be regarded as due to the recent destructive earthquake. In the present note, the changes in heights of the bench marks along the western coast of the Peninsula will be briefly discussed.

Fig. 1.

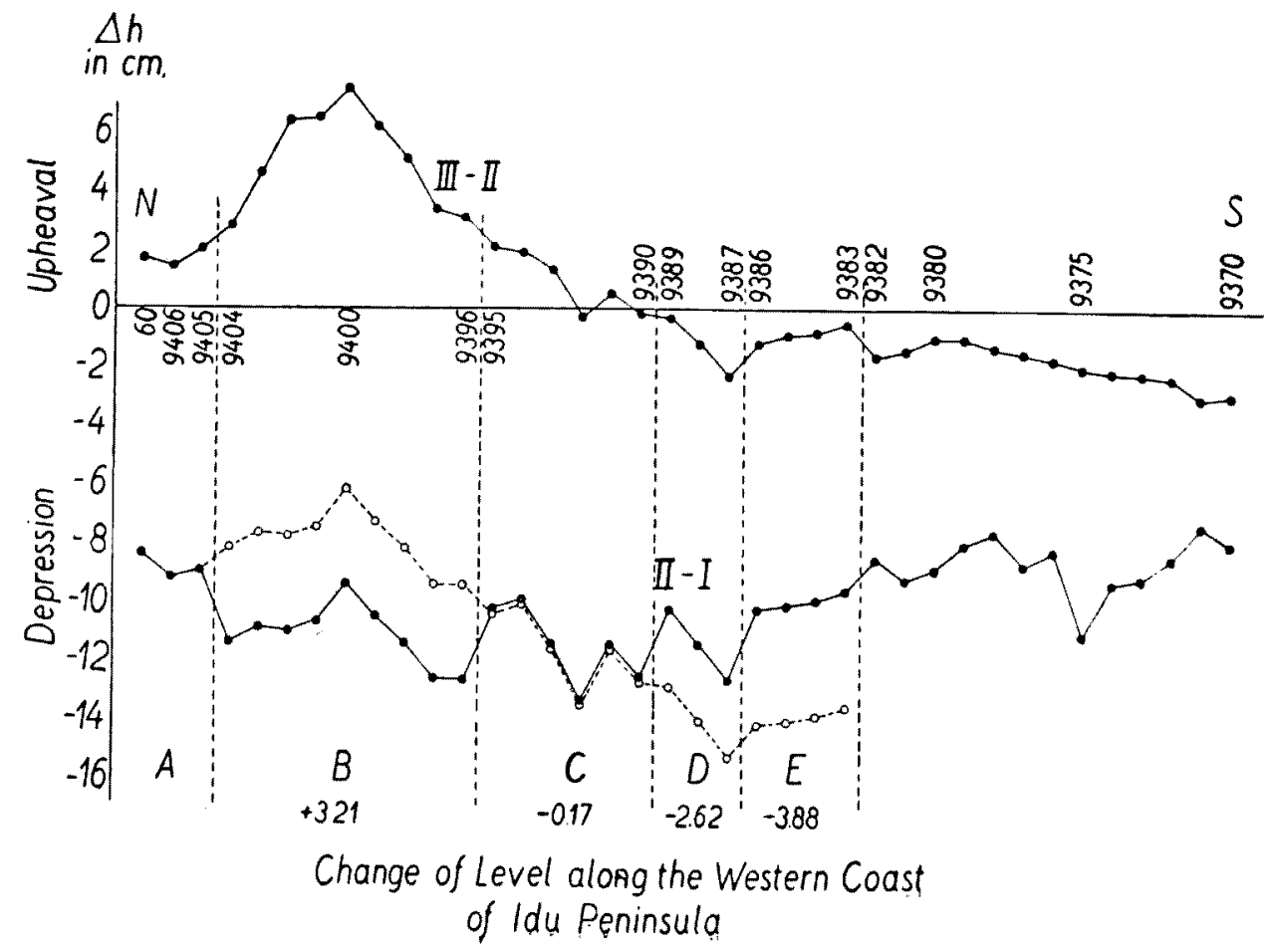


In Fig. 2 is shown the levelling route covered by the new survey. The numberals in the map are the ordinal numbers of the bench marks

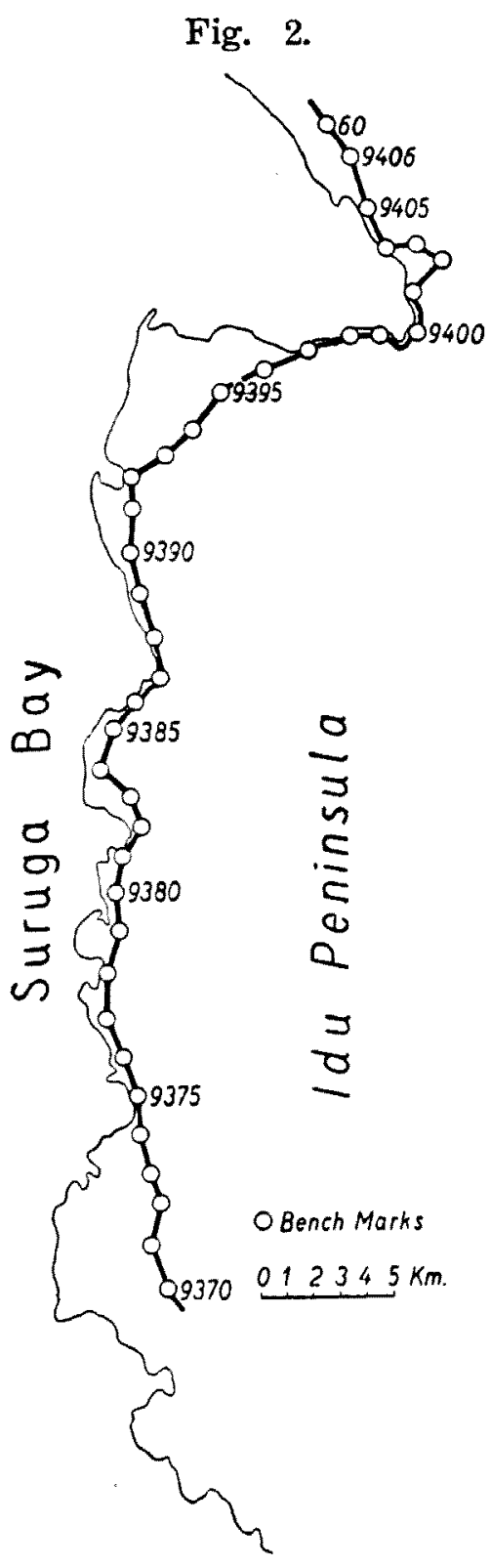
in the route. The curve III-II in Fig. 1 represents the changes of heights of the bench marks as found by the comparison of the results of the levellings made before and after the recent destructive earthquake. The curve II-I in the same figure represents the same before and after the great Kwanto earthquake of 1923 .

When the two curves II-I and III-II are compared, there are found a number of corresponding segments or portions such as $\mathrm{A}, \mathrm{B}, \mathrm{C}, \mathrm{D}$ and $\mathrm{E}$ which are quite similar in their forms for the two curves. If these segments $\mathrm{B}, \mathrm{C}, \mathrm{D}$ and $\mathrm{E}$ in the curve II-I are displaced $3.21 \mathrm{~cm},-0.17 \mathrm{~cm}$, $-2.62 \mathrm{~cm}$ and $-3.88 \mathrm{~cm}$ respectively along $\Delta h$-axis, we have a new curve which is shown by the broken lines in Fig. 1. This curve is again very much similar to the curve III-II in its form. These circumstances would seem to indicate the block structure of the district now in question. The segments $\mathrm{A}, \mathrm{B}, \mathrm{C}, \mathrm{D}$ and $\mathrm{E}$ may be regarded to be corresponding to land blocks. The similarity in form of the corresponding segments in the two curves indicates that each of these land blocks has long been subjected to an approximately same mode of tilting. That the mean relative ordinates of the corresponding segments are different for the two curves indicates that each of these land blocks has undergone, besides the tilting movement, a vertical movement which is apparently independent from that of the neighbouring ones.

The levelling routes in the land blocks $\mathrm{A}, \mathrm{D}$ and $\mathrm{E}$ are nearly straight in their trends and their tiltings are of similar type as those found in the Tango district connected with the Tango earthquake of 1927."

1) C. Tsuboi: Proc. 4 (1928), 529 ; Bull. Earthq. Res. Inst., 8 (1930), 153. 
The levelling route between B:M. 9404-9396 in the segment B is not straight but is bent with large curvatures. The particular shape of the curve in Fig. 1 corresponding to the changes of heights of these bench marks needs therefore to be treated by a special method, for example, the method due to N. Miyabe." ${ }^{1)}$ For this purpose, the azimuths of the lines connecting any two of these bench marks in different combinations and the corresponding gradients of the change of heights along these directions were calculated from the results of the surveys. If the relative changes of heights of the bench marks were solely due to a tilting of the land block on which they lie, then the calculated gradient must be a sinusoidal function of the corresponding azimuth. This was approximately the case for the bench marks on the land block $B$ as shown in Fig. 3 and it is clear that the tilting of this

Fig. 3.

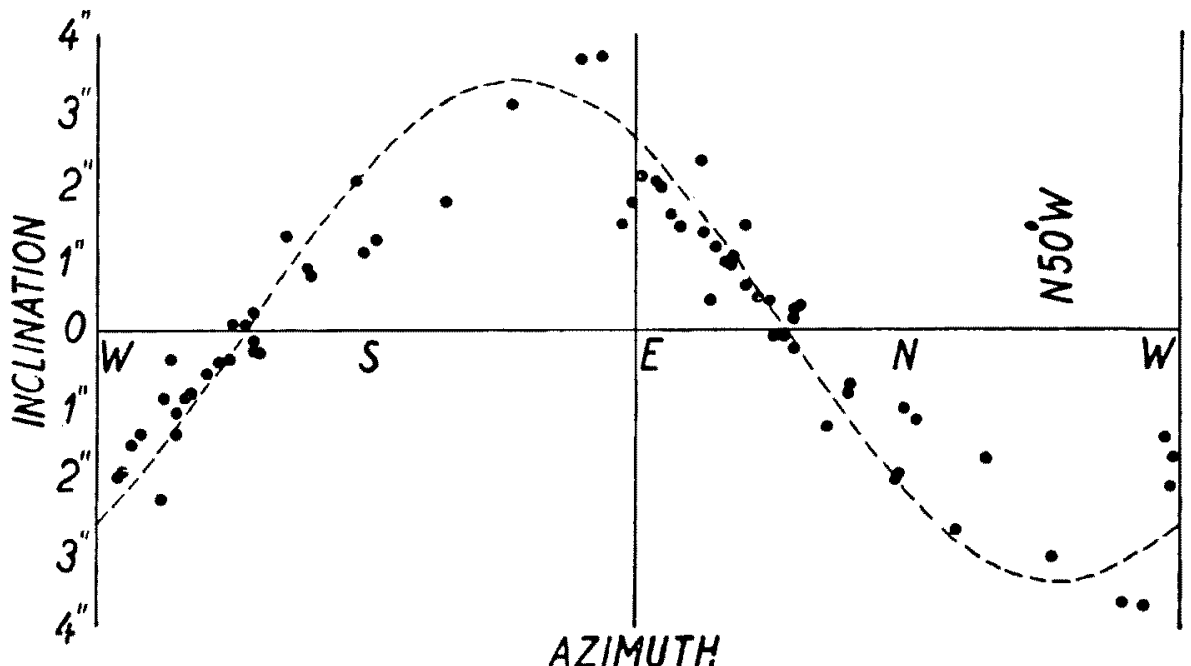

block was down towards $\mathrm{N} 50^{\circ} \mathrm{W}$ and about $4^{\prime \prime}$ in its magnitude. Similarly the tilting of the land block $\mathrm{C}$ was found to have been towards $\mathrm{S} 70^{\circ} \mathrm{W}$ and $5^{\prime \prime}$ in its magnitude. For the southern part of the levelling route from B.M. 9328 south down to B.M. 9370 no clear indication of such block structure is to be found in Fig. 1 and this is rather a remarkable contrast with the structure of the northern part of the same route.

After all, the assumption of the relative movements of more or less rigid land blocks as crustal units seems to become more and more firmly established by the recent accumulations of the geodetic data.

1) N. Miyabe: Proc. 7 (1931), 150. 